\title{
The choice of concrete mixers for the concrete preparation
}

\author{
Batraz Kaitukov, Mihail Stepanov and Pavel Kapyrin* \\ Moscow state University of Civil Engineering, 26, Yaroslavskoye Shosse, Moscow, Russia, 129337
}

\begin{abstract}
The production of commodity concretes is a large segment of the construction industry and a testing base for concrete mixers. The choice of high-reliable concrete mixers for high-quality production of various brands of concrete is topical. When choosing concrete mixers, the most important is condition for improving the quality of mixing. Solving this problem, the analysis of various parameters and structural designs of concrete mixers is carried out. Dependencies are established that show the properties of concrete of various brands with their composition and technical characteristics of concrete mixers. Variants of rational selection of concrete mixers that provide high uniformity of concretes and a combination of the components of the mixture are proposed. The capacities of various concrete mixers for the preparation of commodity concrete are determined and the optimum rotational speeds of the working elements of concrete mixers are determined. Reasonable speeds of movement of working elements are revealed and dependences of the Reynolds number on frequency of rotation of a drum between capacity and diameter of a drum of a concrete mixer are established. This method of selecting rational concrete mixers allows reducing operating costs and improving the quality of concrete.
\end{abstract}

\section{Theoretical and practical background}

The production of various brands of concrete is an intensively developing direction of the construction industry. This segment of construction production remains a major redistribution of the construction market and is a production base for concrete mixers. The main requirement for the preparation of high-quality, low-mobility, rigid and highly rigid concrete mixtures is the condition for a uniform distribution of the components of the mixture along the volume of the mixing drum. The fulfillment of this condition assumes the production of concrete of high uniformity and strength. However, the proposed concrete mixers do not always fully ensure the uniformity of the mixture and the preparation of the required brands of concrete. The solution to this problem involves the selection and design of new reliable concrete mixers.

Survey objective: determination of advantages and peculiarities of concrete mixer operation in the preparation of various types of concrete of any workability and watercement ratio by analyzing technical and economic indicators and their construction.

*Corresponding author: SevryuginaNS@mgsu.ru 


\section{Analysis of basic provisions}

Currently, there is an in-depth study of the regularities connecting the properties of concrete with its composition, technical characteristics and capabilities of various designs of concrete mixers. The carried out analysis of technical and economic indicators and design of concrete mixers allowed to determine their advantages and features of work in the preparation of various brands of concrete of any workability and water-cement ratio [1, 2]. In concrete mixers of compulsory action, the orbits of the motion of particles of components of a concrete mixture have forced character, which is determined by the motion of the rotor with blades. When the blade is installed parallel to the longitudinal axis of the concrete mixer with the mixture, it experiences resistance to movement from frictional forces. To determine the rational arrangement of the blades, it is necessary to establish the relationships between the characteristics and properties of concrete and the parameters of concrete mixers. The motion of a concrete mixture with the interaction of rotating horizontal shafts on it can be described by the system of Navier-Stokes equations [3].

Studies of different kinematic schemes and designs of concrete mixers have shown that huge design work has led to a great variety of their parameters, schemes and layouts $[1,2$, 4]. The analysis made it possible to reveal the dependence of the mixing time required for the preparation of the desired brand of concrete as a function of the speed of the blades [4, 5]. The load and power of the concrete mixer motor are significantly influenced by the kinematic parameters and the speed of blades rotary mixer. For concrete mixers of domestic and foreign production speed of the blade is in the range of $1.4 \ldots 3.5 \mathrm{~m} / \mathrm{sec}$. With a rational increase in the speed of motion of the rotor blades of the forced concrete mixers to a certain condition, a more even distribution of the components of the mixture can be obtained in a shorter mixing time.

\section{Development of a modified methods}

In gravitational concrete mixers, a concrete mixture is obtained by repeatedly lifting the components of the mixture, and then under the influence of friction forces which are falling down. These concrete mixers with increasing capacity of loading reduce the speed of the drum, and with increasing speed, the engine power is increased.

When choosing a rational concrete mixer from the variety offered, it is required to establish some rules. Among them:

- to reveal the physics of the process of mixing the components of the mixture;

- to reveal the dependencies allowing to increase the quality of the mixture depending on the design of the concrete mixer;

- to determine the optimal design of concrete mixers in the preparation of quality brands of concrete.

In order to obtain the required homogeneity of the mixture, the particles of the original components must be provided with such trajectories of motion that would ensure the greatest possibility of their intersection in the concrete mixer casing.

A significant indicator at the macro level is the rational distribution of the components of the concrete mix by its volume. It seems reasonable to determine the degree of homogeneity, taking into account not only the strength of the concrete for compression and its density, but also the circumferential speed of the mixer's working element, the shape of the grains of the coarse aggregate. This approach allows you to choose the right landmarks when designing different mix compositions and choosing the mixing methods and mixing equipment. In existing concrete mixers the lack of work is their low averaging capacity. 
The combination of different types of motion of the components of the mixture in the working space of the concrete mixer at the optimum rotation frequencies of their working elements allows providing complex movement of particles of a mixture. This makes it possible to intensify the mixing process and, as a result, the productivity of the concrete mixers increases.

In order to select the most rational design of the concrete mixer and the optimal trajectories of the mixture components, an analysis of the construction of various concrete mixers, the current state of production of this equipment and patent search were carried out in the production of quality concretes [1-8].

For example, comparing the parameters of concrete mixers of the company ZZBO (Russia, Zlatoust) Zlatoust Plant concrete mixing equipment, the key values are options: volume - "litres"; performance "cube. meters"; the volume of the batch of concrete "litres"; time stirring the mixture - "seconds", at the same time the parameter placeholder size remains unchanged-no more $70 \mathrm{~mm}$.

Analytical researches help to choose roster concrete mixers option, but do not show the detail of the consumer benefits of choosing one or another model [7-10].

The some option is applied by most European manufacturers of concrete mixers, such as: (IMER International S.p.A., Komplet Italia S.r.l., Simem S.R.L., Officine Piccini S.p.A., SKAKO CONCRETE Italy; KNIELE Baumaschinen GmbH, BHS Sonthofen Germany; CreteAngle Britain; ARCEN (Асен), Portugal; Kardelen Makina Turkey; Altrad Group (France); FILAMOS, s. r. o. (Czech Republic); Oliano Cuoghi; IMER Group; Ocmer; OMAER; SIMEM etc.

After studying the experience of the invention and analyzing the design of various mixing mechanisms for the production of mixtures, we chose the concrete mixer "Turbul" of the Swiss company "Willy A.Bachofen" [6-7]. The concrete mixer consists of a bed, a leading and a driven shaft fixed in hinge pins on diametrically mutually perpendicular axes. A complex double elliptical movement with a change in the angle provides all the degrees of freedom to the concrete particles to be mixed, thereby facilitating their intensive and qualitative mixing.

The trajectories of particle motion and the forces acting on the material point in such concrete mixers are determined depending on the dimensions of the mixing working element [9].

Frequency of rotation of the mixing drum or rotor of the concrete mixer, ${ }^{1} / \mathrm{sec}[2]$ :

$$
n=\frac{(0.25 \ldots 0.35)}{\sqrt{R}},
$$

Where $R$ is the inner radius of the drum, $\mathrm{m}$.

At $R=0.85 \mathrm{~m}$, for concrete mixers (800 liters), the rotation frequency according to (1) is defined as: $n=0.223 \ldots 0.356^{1 /} / \mathrm{sec}$., we take the average value $n_{\text {mid }}=0.29{ }^{1} / \mathrm{sec}$. To drive the mixing element, it is necessary to select the motor using an 800 litres, mixer as an example, according to (3), the calculated power is $4.9 \mathrm{~kW}$, select the motor $4 \mathrm{~A} 132 \mathrm{~S} 6 \mathrm{Y} 3$, the power $P_{\text {mot }}=5.5 \mathrm{~kW}$ and the speed $n=975^{1} / \mathrm{min}[1]$.

The productivity $G$ [2] of the concrete mixer is determined from the dependence, $\mathrm{m}^{3} /$ hour :

$$
G=\frac{V_{3} \cdot Z \cdot K_{o r} \cdot K_{y c}}{1000}
$$

Where $V_{3}$ - volume of loading, $\mathrm{m}^{3}$;

$K_{o r}$ - the output ratio of the mixer, $0.65 \ldots 0.7$;

$K_{y c}$ - is the yield coefficient of the mixture, $0.85 \ldots 0.9$; 
$Z$ - number of mixtures in, hour.

The power of concrete mixers is determined by the dependence, $\mathrm{kW}$ :

$$
P_{W}=\frac{P_{1}+P_{2}}{\eta},
$$

Where $P_{1}$ - power per rotation of the mixer's working part, $\mathrm{kW}$;

$P_{2}$ - power to overcome the resistance while stirring, $\mathrm{kW}$;

$\eta$ - energy conversion efficiency.

\section{Results}

The analysis showed that concrete mixers with a loading volume of 800 liters and a final mixture yield of 750 liters are most often used. According to Figure 1, the performance of such a concrete mixer is $-11 \mathrm{~m}^{3} /$ hour. To determine the capabilities of a concrete mixer with a loading capacity of 800 liters, it is necessary to select mixtures and its components and set the Reynolds number. Taking into account the technical characteristics of this concrete mixer, concrete of class $B 30$ was chosen, as a result of mixing, concrete of the required strength of $29.8 \mathrm{MPa}$ was obtained. Freshly prepared concrete mix meets the requirements of homogeneity, workability and density. An important characteristic for viscous liquids, including mixtures, is the Reynolds number. When the Reynolds number exceeds the critical value, the laminar flow becomes turbulent, in which the particles of matter make chaotic motion along complex trajectories.
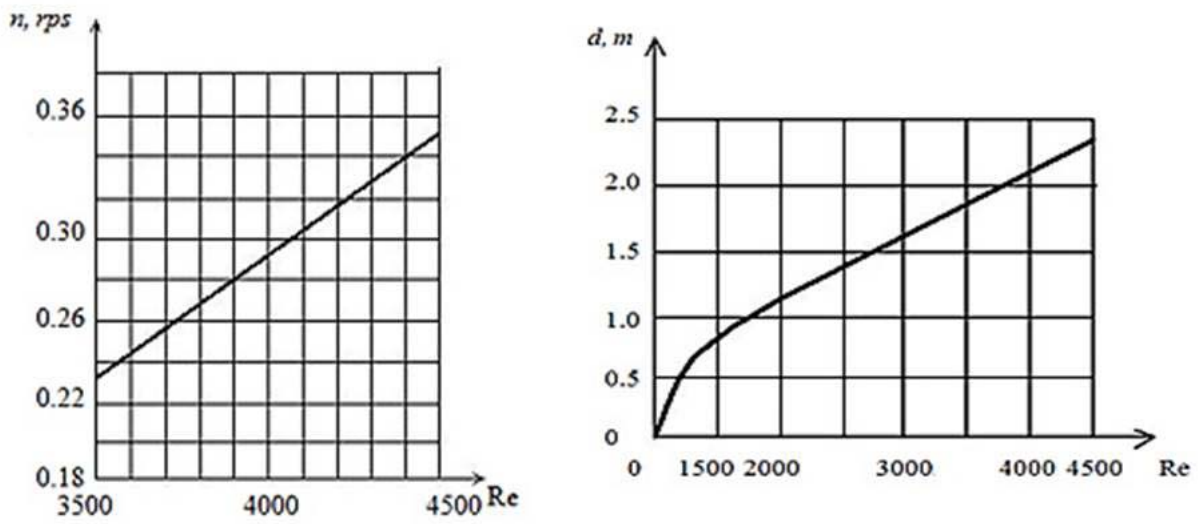

Fig 1. Dependence of the Reynolds number on the rotational speed of the drum, and on the diameter of the drum [2].

In general, the Reynolds number is expressed by the ratio of the inertia forces to the viscosity of the material and is determined from the dependence [2]:

$$
R_{e}=\frac{V \cdot d \cdot \rho}{v},
$$

Where $V$ - the characteristic velocity, $0.332 \mathrm{~m} / \mathrm{sec}$. at $n=0.291 / \mathrm{sec}$;

$n$ - frequency of rotation of the bowl of a gravity concrete mixer, $0.291 / \mathrm{sec}$.;

$d$ - characteristic geometric size of the drum, $1.9 \mathrm{~m}$;

$\rho$ - density of the material, $1800 \mathrm{~kg} / \mathrm{m}^{3}$;

$v$ - the dynamic viscosity of the moving medium, $0.28 \mathrm{~Pa}$ 's. 
The most reliable hypothesis for this phenomenon is the change in the fluid flow regimes, determined by the ratio of the inertia forces to the viscous forces in the fluid flow. If the first predominate, then the regime of motion is turbulent, if the second one it is laminar. Turbulent flows occur at high fluid velocities and low viscosity, laminar flows occur in slow flow conditions and in viscous liquids. To obtain a homogeneous mixture, turbulent flow is more preferable. Therefore, in order to obtain a stable turbulent mixing regime, it is necessary to set such an optimum rotation speed of the mixing drum and the Reynolds number in order to obtain a homogeneous mixture. According to (4), for 800 liters concrete mixer, the calculated value is $R_{e}=4061$, but under the condition $R_{e}>4000$ the mode is turbulent, then $R_{e}=4000<4061$, hence the regime is turbulent. When determining the optimum values of the rotational speed of the drum of a concrete mixer, it is important to know their dependence on the Reynolds number. The change in the frequency of rotation of the drum from the Reynolds number can be determined from the dependence:

$$
n\left(R_{e}\right)=\frac{2 \cdot v \cdot R_{e}}{d^{2} \cdot \rho},
$$

When setting the energy intensity of the concrete mixer, it is required to know the effect of the drum diameter and the mass of the concrete mixer on the power, the dependence of the diameter of the drum on power, determined by the formula:

$$
P(d)=P_{1}(d)+P_{2}(d)
$$

Figure 1 shows the dependence of the Reynolds number on the rotational speed of the drum of the concrete mixer.

When choosing the geometric parameters of the mixing drum, it is important to know the dependence of the change in diameter on the Reynolds number, and in drum diameter on the Reynolds number, which is determined from the dependence:

$$
d=\sqrt{\frac{2 \cdot v \cdot R_{e}}{n \cdot \rho}},
$$
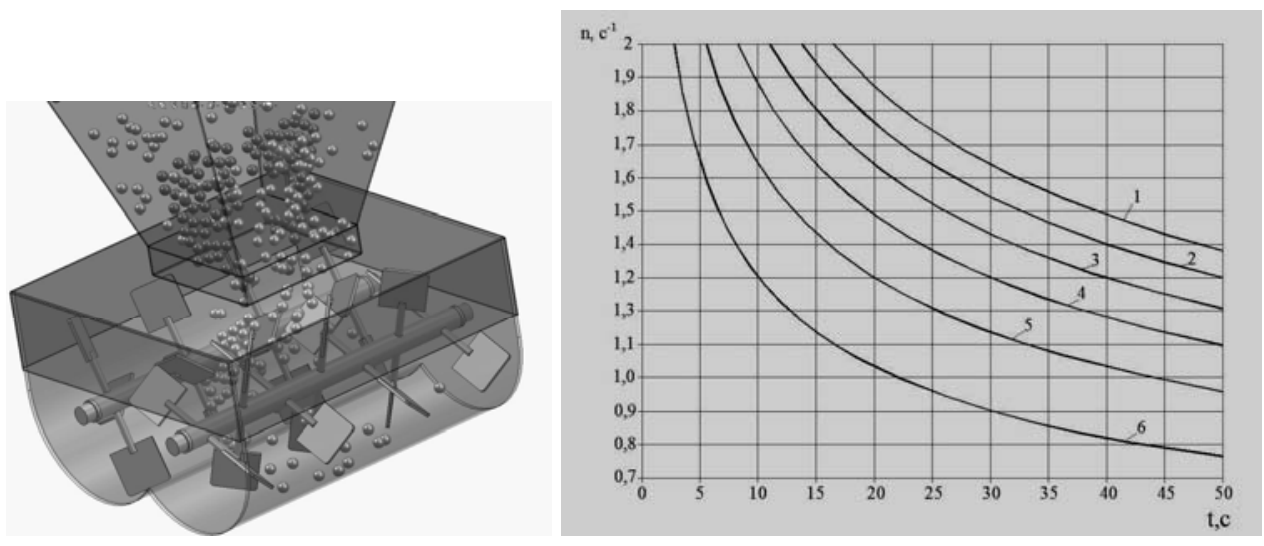

Fig 2. Nomogram for determining the optimal parameters of mixer.

Nomogram for determining the optimal settings of the rotation frequency of the blade shafts $\mathrm{n}$ and the length of the mixing process $\mathrm{t}$ in twin mixer mixes with different resistivity movement of the blade in the mix $\mathrm{p}$ given the degree of separation Figure 2:

$1-P=60 \mathrm{kPa} ; 2-P=50 \mathrm{kPa} ; 3-P=40 \mathrm{kPa} ; 4-P=30 \mathrm{kPa} ; 5-P=20 \mathrm{kPa} ; 6-P=10 \mathrm{kPa}$. 


\section{Discussion}

The conditions of production, which are economical in the use of faucets constitute an area of their rational application. In turn, the field of rational use of mixers is a zone of changes in the parameters characterizing the working conditions of the mixer, in which this mixer provides the greatest economic efficiency compared to others. With a sufficient degree of reliability, it can be argued that the targeted modernization involves expanding the field of rational use of mixers in the process of their operation and increases their efficiency [8-10].

\section{Conclusions}

The choice of rational concrete mixing equipment for the preparation of high-quality concrete, assumes an optimal selection of parameters and characteristics of concrete mixers depending on the Reynolds number. This approach provides rational selection of concrete mixing equipment and a qualitative process of mixing concrete, their intensification and mechanization. Simultaneously with the increase in uniformity and strength of concretes, the energy consumption for preparing mixtures is reduced by $15-17 \%$ and the reliability of the concrete mixers increases.

\section{References}

1. Yu. I. Gustov, M. A. Stepanov, B. A. Kaitukov. Mech. of const. 12. 30-31 (2013)

2. Yu. I. Gustov, B. A. Kaitukov, M. N. Grigoriev. Mech. of const. No. 11. 26-29. (2016)

3. A. M. Gridchin, V. V. Yadykina, A. I.Trautvain, R. R. Sharapov, A. A. Zhukova. Research Journal of Applied Sciences. Vol. 9. No. 12. p. 1053-1058. (2014)

4. V. I. Telichenko, B. A. Kaitukov, V. I. Skell. BulBelgSt.Un. V. G. Shukhov. 2.. 178-180 (2017)

5. V. I.Telichenko, B. A. Kaitukov, V. I. Skell. BulBelgSt.Un. im. V. G. Shukhov. .3. 80-84 (2017)

6. RF Patent 2010707. The gravitational mixer

7. RF patent 2014227. Gravity mixer building material

8. S. Yu. Lozovaya, I. A. Lymar, BulBelgSt.Un. im. V. G. Shukhov.. 2. 52-55 (2012)

9. E. V. Kharlamov, R. R. Sharapov, M. A. Stepanov. The scientific review. 12. 99-101 (2013)

10. V. A. Zorin, V. A., Daugello, N. S. Sevryugina, Belgorod: Publishing house BGTU im. V. G. Shukhov, (2009) 